\title{
Diagnostic Performance of Mean Platelet Volume in the Diagnosis of Acute Myocardial Infarction: A Meta-Analysis
}

Kathrina Aseanne Acapulco, Shayne Julieane Morales, Tzar Francis Verame

Department of Pathology, Perpetual Succour Hospital, Cebu City, Philippines

\section{ABSTRACT}

Objective. The aim of this systematic review and meta-analysis is to determine summary estimates of the diagnostic accuracy of mean platelet volume for the diagnosis of myocardial infarction among adult patients with angina and/or its equivalents in terms of sensitivity, specificity, diagnostic odds ratio, and likelihood ratios.

Methodology. The primary search was done through search in electronic databases. Cross-sectional, cohort, and case-control articles studying the diagnostic performance of mean platelet volume in the diagnosis of acute myocardial infarction in adult patients were included in the study. Eligible studies were appraised using well-defined criteria.

Results. The overall mean MPV value of those with MI $(9.702 \mathrm{fl} ; 95 \% \mathrm{Cl} 9.07-10.33)$ was higher than in those of the non-Ml control group ( $8.85 \mathrm{fl} ; 95 \% \mathrm{Cl} 8.23-9.46)$. Interpretation of the calculated t-value of 2.0827 showed that there was a significant difference in the mean MPV values of those with MI and those of the non-MI controls. The summary sensitivity (Se) and specificity (Sp) for MPV were 0.66 (95\% Cl; $0.59-0.73)$ and 0.60 (95\% Cl; $0.43-0.75)$, respectively. The pooled diagnostic odds ratio (DOR) was 2.92 (95\% Cl; $1.90-4.50$ ). The positive likelihood ratio of MPV in the diagnosis of myocardial infarction was 1.65 (95\% Cl; $1.20-22.27$ ), and the negative likelihood ratio was 0.56 (95\% Cl; $0.50-0.64)$

Conclusion. The intended role for MPV in the diagnostic pathway of myocardial infarction would perhaps be best as a triage tool. MPV values can discriminate between those who have Ml and those without. For a patient with angina presenting with elevated MPV values, it is 1.65 times more likely that he has MI. It is implied that the decision to treat a patient with angina or its equivalents as a case of $\mathrm{MI}$ could be supported by an elevated MPV value.

Key words: mean platelet volume, MPV, myocardial infarction, angina, chest pain

ISSN 2507-8364 (Online)

Printed in the Philippines.

Copyright $(0) 2020$ by the PJP.

Received: 7 October 2020.

Accepted: 2 December 2020.

Published online first: 16 December 2020.

https://doi.org/10.21141/PJP.2020.11

Corresponding author: Kathrina Aseanne C. Acapulco, $M D$

E-mail:kcacapulcomd@gmail.com

\section{INTRODUCTION}

\section{Rationale}

The World Health Organization identifies Cardiovascular Diseases (CVD) as the top cause of death worldwide with an estimated 17.9 million deaths annually. Four out of five cardiovascular deaths are due to myocardial infarction and stroke. ${ }^{1}$ Acute Coronary Syndrome (ACS) refers to a spectrum of conditions which are consistent with acute myocardial ischemia and/or infarction that are most likely due to an abrupt reduction in coronary blood flow. ${ }^{2}$ These conditions include: Unstable Angina (UA), Non-ST Segment Elevation Myocardial Infarction (NSTEMI), and ST-Segment Elevation Myocardial Infarction (STEMI).

The diagnosis of myocardial infarction relies on a constellation of anginal symptoms combined with findings on electrocardiograms (ECGs) and biomarkers of myocardial necrosis. Among these biomarkers, cardiac troponins are the most specific and most sensitive. ${ }^{2}$ However, the diagnostic efficiency of these cardiac troponin measurements within 2 to 4 hours of symptom onset is limited. ${ }^{3}$ Furthermore, the challenge remains upon Filipino physicians to make rapid and accurate diagnoses in institutions that may not have access to these life-saving diagnostic modalities. 
As an integral component in the pathogenesis of myocardial infarction, thrombus formation is brought about by plaque disruption and subsequent exposure of substances that promote platelet activation, adhesion, aggregation, and thrombin generation. Platelets therefore play an important role in its pathologic process.

Previous studies have shown that platelet size may be used as a marker for platelet function, such that larger platelets are more active and have a greater tendency for thrombosis. ${ }^{4}$ Mean platelet volume (MPV) is the most accurate measure of the size of platelets and is routinely measured by most automated hematological analyzers together with the complete blood count. Therefore, it is widely available in most healthcare institutions, and the results may be efficiently reported within an hour of blood collection.

Mean platelet volume is an indicator of platelet activation and is a machine-calculated measurement of the average size of platelets. ${ }^{5}$ The methods of analysis of platelet parameters utilize either electrical impedance or optical principles, and recent studies imply that this analysis is not routinely subjected to specific standardization and calibration guidelines. ${ }^{6}$ Although its measurement provides clinically useful data, MPV remains to be a diagnostic tool that is yet to be included in routine clinical decision making.

Several studies have shown associations between mean platelet volume and cardiovascular risks and outcomes, such as risk of acute coronary syndrome and myocardial infarction, re-stenosis and mortality rates after percutaneous coronary intervention (PCI), and even recurrence of myocardial infarction. Furthermore, some studies demonstrate the diagnostic utility of MPV as an early and independent predictor of acute coronary syndrome in patients presenting with chest pain. ${ }^{7}$ However, conflicting data exists such that some studies refute these findings, while most differ on the cut-off point at which to define an MPV value as "elevated." To date, no general consensus exists on the clinical validity of mean platelet volume (MPV) in the diagnosis of myocardial infarction.

\section{RESEARCH QUESTION}

Among adult patients presenting with angina and/or its equivalents, what is the diagnostic performance of an elevated mean platelet volume value in the diagnosis of acute myocardial infarction?

\section{OBJECTIVES}

\section{General Objective}

To determine summary estimates of the diagnostic accuracy of mean platelet volume for the diagnosis of myocardial infarction among adult patients with angina and/or its equivalents.

\section{Specific Objectives}

1. To determine the difference of the mean platelet volume values between those with myocardial infarction and those in the non-MI controls.

2. To determine the sensitivity, specificity, likelihood ratios, and diagnostic odds ratio of mean platelet volume in the diagnosis of myocardial infarction among adult patients presenting with angina and/or its equivalents compared to without MI.

\section{METHODOLOGY}

Literature search, quality assessment of the included studies and data extraction for diagnostic accuracy were conducted by two reviewers (K.A. and T.V.). Discrepancies were discussed and referred to a third reviewer. This metaanalysis followed a predetermined protocol described in the following paragraph. Standard systematic review techniques, as outlined by the Preferred Reporting Items for Systematic Review and Meta-Analysis (PRISMA), were used for this study.

Approval from the hospital Institutional Review Board was secured.

\section{ELIGIBILITY CRITERIA}

Types of Studies. Cross-sectional, cohort, and case-control articles studying the diagnostic performance of mean platelet volume in the diagnosis of acute myocardial infarction in adult patients were included in the study. In the search strategy, studies were included if: (1) CBC was taken upon presentation to the ER or upon admission (within 24 hours of symptom onset); (2) myocardial infarction was diagnosed with serum markers, ECG, or according to accepted guidelines by the Cardiology societies (American Heart Association (AHA), American College of Cardiology (ACC), European Society of Cardiology (ESC); and, (3) if outcomes were measured as significant difference AND/OR sensitivity and specificity. Only publications with English language were selected. No publication status restrictions were imposed. Case reports and/or case series articles were excluded. In addition, studies were also excluded if: study populations comprised of patients with significant comorbidities with expected increase in platelet counts and MPV; articles with inaccessible full text; the study population is not the population of interest (e.g. children) and articles without a control group; however, no restrictions with regards to the type of control were placed (whether the control group are healthy individuals or with non-cardiac chest pain).

Types of participants. Studies with the following participants were included: (1) Adult participants at least 18 years old with angina and its equivalents (dyspnea, shoulder or arm pain, vomiting, diaphoresis), OR (2) Patients with known coronary artery disease; AND the diagnosis of acute coronary syndrome was made using serum markers, ECG, or according to accepted guidelines by the Cardiology societies (American Heart Association (AHA), American College of Cardiology (ACC), European Society of Cardiology (ESC) upon admission or at the emergency department (ED) level.

\section{Language. English}

Characteristics of Diagnostic Tests. Studies evaluating the index test (mean platelet volume) in patients with myocardial infarction (MI) compared with those healthy controls or non-MI were examined. The mean platelet 
volume should have been measured by automated hematology analyzers; and measurement should have been taken upon presentation to the ER or upon admission (within 24 hours of symptom onset). Only MPV values measured in femtoliter using automated analyzers or cell counters were included in this study, regardless of the machine manufacturer or defined reference ranges imposed by each company. For this study, the reference test was the clinical diagnosis of myocardial infarction (MI) with the aid of serum markers (CK-MB and/or Troponin I) and ECG findings which were according to accepted guidelines by the different Cardiology societies (American Heart Association (AHA), American College of Cardiology (ACC), European Society of Cardiology (ESC). Studies that further grouped the acute coronary syndrome (ACS) spectrum into unstable angina (UA), nonST elevation segment myocardial infarction (NSTEMI), and ST-segment elevation myocardial infarction (STEMI) were also included. Studies that did not specify the type of ACS were excluded. Studies with healthy control groups and control groups with co-morbidities (coronary artery disease) or with initial presentation of angina were allowed.

Time Frame. Studies published and indexed between 1990 until 2020 were included.

\section{Types of Outcome Measures}

Primary Outcomes. Diagnostic performance of MPV in the diagnosis of MI that was expressed as summary Sensitivity, Specificity, Positive Likelihood Ratio, Negative Likelihood Ratio, and Diagnostic Odds Ratio; Significant difference in the mean MPV values between those diagnosed with MI and those of the control group.

\section{SEARCH METHODS FOR IDENTIFICATION OF STUDIES}

The primary search was done through search in electronic databases like MEDLINE via PUBMED (https:// www.ncbi.nlm.nih.gov/pubmed/), Cochrane ReviewCENTRAL [Cochrane Central Register of Controlled Trials (http://cochranelibrary-wiley.com/cochranelibrary/
search?searchRow.searchOptions.searchProducts=clinical TrialsDoi)], HERDIN [Health Research and Development Information Network (http://www.herdin.ph)], Google Scholar (http://scholar.google.com), Philippine Journal of Pathology (https://philippinejournalofpathology.org/ index.php/PJP), and Philippine College of Physicians Philippine Journal of Internal Medicine (https://www. pcp.org.ph/index.php/pjim/pjim. The reference list of original reports was also searched. Three study authors, one Bangladeshi (Islam 2017), one British (Mathur 2001) and the other a Chinese (Liang 2017), were contacted through e-mail to acquire full text publications of their studies but to no avail.

MeSH terms used for key and text word searching were as follows: "mean platelet volume" OR "MPV OR "mean platelet concentration" AND "myocardial infarction" OR "acute coronary syndrome" OR "chest pain" OR "angina" OR "dyspnea” OR "anginal equivalent”. Bibliography for relevant citations were manually searched and experts in the field were contacted to ensure completeness of search strategy. Titles and abstracts of potential articles identified in the primary search were evaluated and a list of potential eligible studies were identified. Studies which fulfilled the selection criteria were included in the metaanalysis. No publication status restrictions were applied.

\section{DATA COLLECTION AND ANALYSIS}

\section{Study Selection}

The titles and abstracts of each individual study were screened initially to exclude irrelevant reports. Eligibility assessment was performed independently in an unblended standardized manner by two reviewers. Disagreement between the reviewers was resolved by consensus after a thorough discussion among the reviewers. The reviewers started with a large number of identified records that passed the preliminary criteria. The researchers then sequentially excluded records according to the eligibility criteria. Studies which passed the eligibility criteria were then reviewed in its full text publication. The flow diagram summarizing the flow of studies through the selection process is shown in Figure 1.

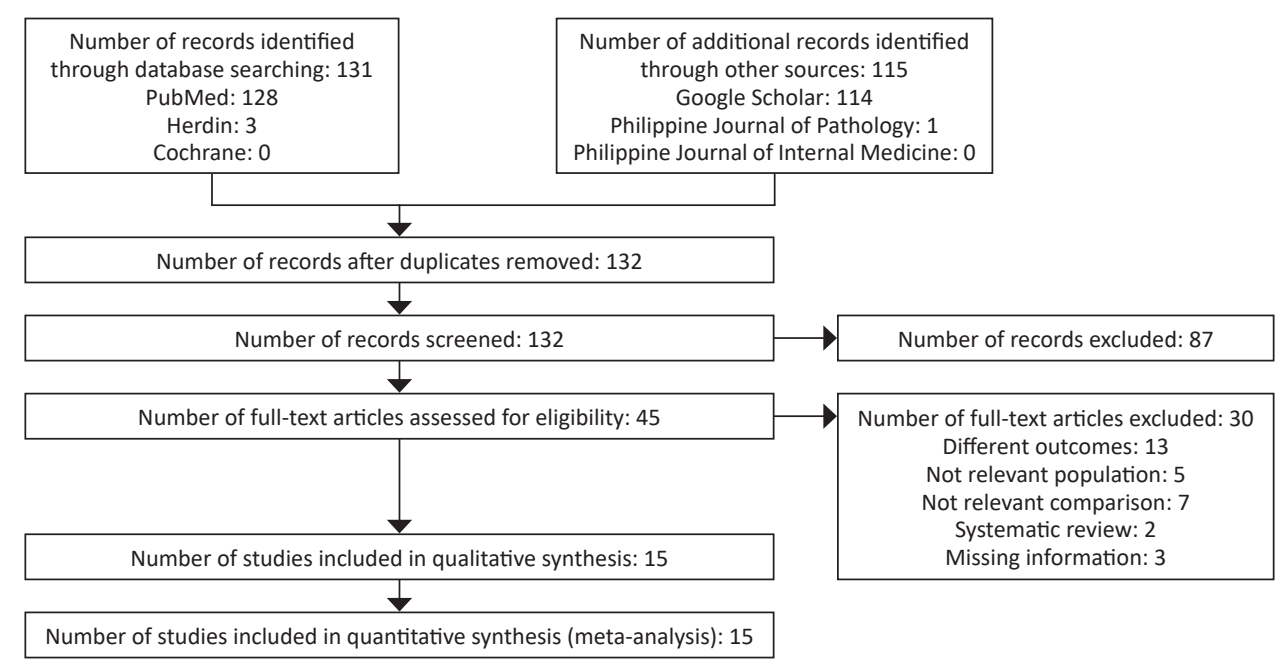

Figure 1. Flow diagram of the Study Selection Process. 


\section{Data Extraction and Management}

Full manuscripts of eligible studies were independently reviewed by the author and another reviewer. Relevant data were extracted into a data collection electronic form (Appendix 1). The following data were extracted:

a. Study characteristics: author, year of publication, country, study design

b. Population characteristics: with exclusion criteria, characteristics of control group, study population size and characteristics

c. Index test characteristics: timing of sampling, analyzer used

d. Reference characteristics: guidelines used in the diagnosis of MI

e. Outcomes: mean MPV values in MI, mean MPV values in control, sensitivity, specificity, threshold

The information obtained were summarized and presented in evidence tables (Appendices 2 and 3). Disagreements between the data extractors were resolved after thorough discussion and review of the eligibility criteria before getting into a consensus.

\section{Assessment of Risk of Bias/Quality Appraisal}

Quality assessment of the studies using QUADAS-2 (Quality Assessment of Diagnostic Accuracy Studies) tool was conducted. Risk of bias assessments was done by one reviewer, with another reviewer providing verification to all of the assessed studies. The QUADAS-2 tool was completed by following stepwise guidelines to judge risk of bias and concerns about applicability for each study (Appendix 4).

\section{STATISTICAL METHODS}

\section{Statistical Outcomes}

Simple descriptive statistics were used to characterize all included studies. Mean MPV values of those with MI were estimated against those of the control groups across all the included articles.

Standard Mean Difference. Across all included articles, the mean MPV values in those with MI were compared with those of the control. Meta-analysis of the standard mean differences was done using the "metan" command. The results were represented graphically in a Forest Plot. In order to investigate whether or not there was a significant difference in the mean values of MPV in those with MI and in those of the control group, a standardized twosample t-test with unequal variances was also performed across all included studies.

Diagnostic Test Accuracy Studies. A total of six diagnostic accuracy studies were deemed eligible for inclusion into the meta-analysis. Sensitivity and specificity values of the index test were determined separately for each study. The "MI" and "non-MI" categories were used to allocate patients into positive and negative, respectively. The diagnoses of "unstable angina" and "coronary artery disease" were allocated as negative. Aided by the RevMan calculator, aggregate data (true positives, false negatives, false positives, and true negatives) were extracted from the individual articles. The RevMan calculator was also used to calculate for the Positive Predictive Value (PPV) and Negative Predictive Value (NPV).
Calculation of metrics. Pooled estimates of sensitivity (Se), specificity ( $\mathrm{Sp}$ ), and their $95 \%$ confidence intervals were calculated as main outcome measures and were analyzed using the "metandi" command to facilitate the fitting of hierarchical logistic regression models. ${ }^{8,9,10}$ The Rutter and Gatsonis HSROC model was used to calculate summary measures of diagnostic accuracy (sensitivity, specificity, positive likelihood ratio, negative likelihood ratio, and diagnostic odds ratio). These measures were pooled using the random effects model. The Rutter and Gatsonis HSROC parametrization model functions of sensitivity and specificity to define a summary ROC curve; whereas the random-effects model assumes that the studies were drawn from populations that differ from each other in ways that could impact on the study effect. ${ }^{11,12}$ These models were used to analyze functions of sensitivity and specificity to define the following:

1. the summary ROC curve,

2. the summary operating point (summary sensitivity and summary specificity),

3. a 95\% confidence region around the summary operating point, and

4. a $95 \%$ prediction region.

Analytical Sensitivity. Analytical sensitivity of the index test (MPV) was evaluated by analyzing the results of the index test (MPV) against the reference standard defined by each study, based on guidelines by the Cardiology societies American Heart Association (AHA), American College of Cardiology (ACC), and/or European Society of Cardiology (ESC).

Variability in Positivity Threshold. As a characteristic source of heterogeneity in meta-analysis of diagnostic test accuracy, presence of the threshold effect was assessed by analyzing the variability of each study's cut-off points to define a positive result. To demonstrate how sensitivity and specificity trade-off with each other as the thresholds vary, summaries of the fitted models were graphically presented as the summary receiver operating characteristic (SROC) curve. Graphical presentations of the summary point, prediction region, and confidence region were also plotted. The "metandiplot" command was used to simplify the plotting of these graphical summaries. Presence of a threshold effect was also evaluated using a Spearman correlation coefficient.

Heterogeneity. In diagnostic test accuracy reviews, heterogeneity has been presumed to exist such that tests for heterogeneity in sensitivity and specificity have not been routinely used since they do not account for heterogeneity explained by phenomena such as positivity threshold effects. ${ }^{11}$ No equivalent to the $\mathrm{I}^{2}$ statistic is currently available for DTA meta-analysis. ${ }^{13}$ Instead, computation of variance under the bivariate model was done. For completion of studies, heterogeneity was evaluated by measurement of $\mathrm{I}^{2}$ values across all included studies.

Statistical Analysis. Data were analyzed using STATA SE13 (StataCorp. 2019. Stata Statistical Software: Release 16. College Station, TX: StataCorp LLC). 


\section{RESULTS}

\section{Description of Studies}

Fifteen articles met the inclusion criteria. Eight articles were diagnostic accuracy studies which gave outcome measures of sensitivity and specificity, while the other seven articles were cross-sectional studies which showed outcome measures of mean MPV values in femtoliters across comparison groups. ${ }^{3,4,7,14-25}$

The characteristics of the studies are presented in Table 1. All of the diagnostic test accuracy studies gave outcome measures of sensitivity and specificity specifically for those with MI, except for two studies (Huang 2019; Kaminska 2018) which only gave outcome measures for ACS without further differentiation into the different subgroups. A total of 9748 adult patients were qualified for inclusion. Two-thousand five hundred forty-six patients (2546) were diagnosed with Myocardial Infarction while 7202 patients were allocated to the non-MI group. The studies were conducted from 2001 to 2019. Most of the studies (12 articles) were conducted in Asia, while two were conducted in Europe and one in North America. All of the included studies limited inclusion to adults with chest pain and/or a diagnosis of an acute coronary syndrome or coronary disease. Majority $(60 \%)$ of the studies employed exclusion criteria, while $40 \%$ of the studies did not specify any exclusions.

\section{Quality Appraisal}

The risk of bias and applicability concern of each study are presented in Table 2. Two review authors independently assessed risk of bias using the QUADAS-2 (Quality Assessment of Diagnostic Accuracy Studies) tool. Risk of bias was assessed in four domains: (1) patient selection, (2) index test, (3) reference standard, and (4) flow and timing. In each domain, the risk of bias was graded as Low, High, or Unclear.

Most of the studies showed low risk of bias. There were applicability concerns regarding patient selection. In 14 out of 15 studies, there was perfect agreement of the QUADAS-2 assessments performed by the 2 review authors. Disagreements were often due to different assessments of the reviewers with regards to patient selection.

\begin{tabular}{|c|c|c|c|c|c|c|c|}
\hline Study No. & Study 1 & Study 2 & Study 3 & Study 4 & Study 5 & Study 6 & Study 7 \\
\hline Author, Year & Assiri 2012 & Cemin 2011 & Chu 2011 & Dehghani 2014 & Huang 2019 & Kaminska 2018 & Khode 2012 \\
\hline Study Design & $\begin{array}{l}\text { Cross-sectional } \\
\text { cohort }\end{array}$ & DTA cohort & DTA cohort & DTA cohort & DTA cohort & DTA case-control & DTA case-control \\
\hline Country & Saudi Arabia & USA & Taiwan & Iran & Taiwan & Poland & India \\
\hline Study Population & $\begin{array}{l}212 \text { with } \\
\text { diagnosis of ACS }\end{array}$ & $\begin{array}{l}1971 \text { with chest } \\
\text { pain }\end{array}$ & $\begin{array}{l}282 \text { with chest } \\
\text { pain }\end{array}$ & $\begin{array}{l}1046 \text { with chest } \\
\text { pain }\end{array}$ & $\begin{array}{l}104 \text { with chest } \\
\text { pain }\end{array}$ & $\begin{array}{l}93 \text { with diagnosis } \\
\text { of ACS }\end{array}$ & $\begin{array}{l}128 \text { with } \\
\text { diagnosis of CAD }\end{array}$ \\
\hline $\begin{array}{l}\text { w/ Exclusion } \\
\text { Criteria }\end{array}$ & Yes & No & Yes & No & Yes & Yes & Yes \\
\hline Control Group & With chest pain & With chest pain & With chest pain & Healthy & With chest pain & Healthy & Healthy \\
\hline Analyzer used & Sysmex & Beckman Coulter & Sysmex & Sysmex & Sysmex & Sysmex & Sysmex \\
\hline Timing of Test & On admission & At ER/ED & At ER/ED & On admission & At ER/ED & $\begin{array}{l}\text { After diagnosis } \\
\text { of ACS }\end{array}$ & On admission \\
\hline \multicolumn{8}{|l|}{ Outcomes } \\
\hline Mean MPV in MI & 8.99 & 7.925 & 11 & 9.7 & 10.7 & 10.8 & 9.65 \\
\hline $\begin{array}{l}\text { Mean MPV in } \\
\text { Control }\end{array}$ & 8.38 & 7.875 & 9.8 & 9.3 & 10.0 & 9.45 & 9.21 \\
\hline Sensitivity & None & $77 \%$ & $78.60 \%$ & $72 \%$ & None & None & $56.40 \%$ \\
\hline Specificity & None & $45 \%$ & $77.6 \%$ & $40 \%$ & None & None & $45.9 \%$ \\
\hline Cut-off Threshold & None & $7.5 \mathrm{fl}$ & $10.65 \mathrm{fl}$ & $9.15 \mathrm{fl}$ & None & None & $9.25 \mathrm{fl}$ \\
\hline
\end{tabular}

Table 1. Characteristics of Included Studies (continued)

\begin{tabular}{|c|c|c|c|c|c|c|c|c|}
\hline Study No. & Study 8 & Study 9 & Study 10 & Study 11 & Study 12 & Study 13 & Study 14 & Study 15 \\
\hline Author, Year & $\begin{array}{l}\text { Kilicli-Camur } \\
2015\end{array}$ & Lippi 2009 & Mirzaie 2012 & Ozlu 2013 & Senaran 2001 & Wang 2016 & Yaghoubi 2016 & Yilmaz 2008 \\
\hline Study Design & DTA cohort & $\begin{array}{l}\text { Cross-sectional } \\
\text { cohort }\end{array}$ & $\begin{array}{l}\text { Cross-sectional } \\
\text { cohort }\end{array}$ & $\begin{array}{l}\text { Cross-sectional } \\
\text { case-control }\end{array}$ & $\begin{array}{l}\text { Cross-sectional } \\
\text { case-control }\end{array}$ & DTA cohort & $\begin{array}{l}\text { Cross-sectional } \\
\text { case-control }\end{array}$ & $\begin{array}{l}\text { Cross-sectional } \\
\text { case-control }\end{array}$ \\
\hline Country & Turkey & Italy & Iran & Turkey & Turkey & China & Iran & Turkey \\
\hline Study Population & $\begin{array}{l}200 \text { who } \\
\text { underwent } \\
\text { angiography }\end{array}$ & $\begin{array}{l}2304 \text { with } \\
\text { chest pain }\end{array}$ & $\begin{array}{l}851 \text { with } \\
\text { chest pain }\end{array}$ & $\begin{array}{l}79 \text { with diagnosis } \\
\text { of ACS }\end{array}$ & $\begin{array}{l}57 \text { with diagnosis } \\
\text { of ACS }\end{array}$ & $\begin{array}{l}1574 \text { with } \\
\text { chest pain }\end{array}$ & $\begin{array}{l}631 \text { with } \\
\text { diagnosis of ACS }\end{array}$ & $\begin{array}{l}216 \text { with } \\
\text { diagnosis of ACS }\end{array}$ \\
\hline $\begin{array}{l}\text { w/ Exclusion } \\
\text { Criteria }\end{array}$ & Yes & No & No & No & No & Yes & Yes & Yes \\
\hline Control Group & With chest pain & With chest pain & With chest pain & Healthy & Healthy & With chest pain & With chest pain & With stable CAD \\
\hline Analyzer used & Sysmex & Siemens & Sysmex & Coulter & Coulter & Sysmex & Sysmex & Sysmex \\
\hline Timing of Test & First 24 hours & At ER/ED & At ER/ED & First 24 hours & On admission & On admission & First 24 hours & First 24 hours \\
\hline \multicolumn{9}{|l|}{ Outcomes } \\
\hline Mean MPV in MI & 11.75 & 8.175 & 9.92 & 8.78 & 8.2 & 9.4 & 10.14 & 10.4 \\
\hline $\begin{array}{l}\text { Mean MPV in } \\
\text { Control }\end{array}$ & 10.89 & 7.7 & 9.57 & 7.78 & 6.6 & 7.9 & 9.34 & 8.9 \\
\hline Sensitivity & $46 \%$ & None & None & None & None & $69.69 \%$ & None & None \\
\hline Specificity & $87 \%$ & None & None & None & None & $50 \%$ & None & None \\
\hline Cut-off Threshold & $12 \mathrm{fl}$ & None & None & None & None & $9.0 \mathrm{fl}$ & None & None \\
\hline
\end{tabular}


Table 2. Quality Assessment of Included Studies using QUADAS-2 Tool

\begin{tabular}{|c|c|c|c|c|c|c|c|}
\hline \multirow{2}{*}{ Study } & \multicolumn{4}{|c|}{ Risk of bias } & \multicolumn{3}{|c|}{ Applicability concerns } \\
\hline & Patient Selection & Index Test & Reference Standard & Flow and Timing & Patient Selection & Index Test & Reference Standard \\
\hline Assiri 2012 & (;) & (;) & (;) & (;) & (i) & (;) & (;) \\
\hline Cemin 2011 & (2) & (;) & (-) & (-) & (-) & (-) & (;) \\
\hline Chu 2011 & (-) & (;) & (-) & (-) & (-) & (-) & (-) \\
\hline Dehghani 2014 & $(2)$ & (;) & (-) & (;) & (;) & (;) & (-) \\
\hline Huang 2019 & (;) & (;) & (;) & (;) & (;) & (;) & (-) \\
\hline Kaminska 2018 & (2) & (2) & (-) & $?$ & (;) & (;) & (;) \\
\hline Khode 2012 & 2 & 2 & (i) & (i) & (i) & (i) & (i) \\
\hline Kilicli-Camur 2015 & (-) & (-) & (:) & (-) & (-) & (-) & (-) \\
\hline Lippi 2009 & 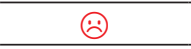 & (:) & (:) & (:) & (-) & (-) & (-) \\
\hline Mirzaie 2012 & 2 & (2) & (i) & (2) & (2) & (2) & (i) \\
\hline Ozlu 2013 & 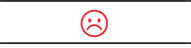 & 2 & (-) & (-) & (-) & (-) & (-) \\
\hline Senaran 2001 & (2) & 2 & (i) & (i) & (i) & (i) & (i) \\
\hline Wang 2016 & (i) & (i) & (i) & (i) & (i) & (i) & (i) \\
\hline Yaghoubi 2013 & 2 & 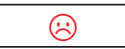 & (i) & (i) & (i) & (i) & (i) \\
\hline Yilmaz 2008 & (2) & (2) & (;) & (;) & (;) & (;) & (;) \\
\hline
\end{tabular}

\section{Outcomes}

Pooled Standard Mean Difference. MPV values were higher in patients with myocardial infarction $(9.702 \mathrm{fl}$; $95 \%$ CI $9.07-10.33)$ than in those of the non-MI control group (8.85 fl; $95 \%$ CI 8.23 - 9.46). Meta-analysis across all fifteen included studies showed a pooled standard mean difference of 1.131 (95\% CI; 0.81 - 1.45) using the Hedges method with random effects model. This value of 1.131 was within the reported normal analytical variation according to a study by Buoro, et al. ${ }^{26}$ This could imply that although there is heterogeneity in the included studies, the variability in MPV values among patients with MI was still within the expected normal range (no significant outliers or deviations). Forest plots for the mean values of MPV in the diagnosis of myocardial infarction are seen in Figure 2. The pooled estimate favors a positive association (increased values) of MPV. Overall heterogeneity for the included studies was measured using $\mathrm{I}^{2}$ with a value of $96.3 \%$.

Significant Difference Between Means. Results of the two-sample t-test with unequal variances and Hedges random effects model showed a t-value of 2.0827 with degrees of freedom at 27.9 , and a t-distribution table value of 2.048. Since the calculated t-value was greater than the t-distribution table value $(2.0827>2.048)$, we can reject the null hypothesis and accept the alternative hypothesis that there is a significant difference in the mean MPV values of those with MI and those of the non-MI controls.

Summary Sensitivity and Specificity. Subgroup analysis of the six diagnostic test accuracy studies showed that the summary sensitivity (Se) and specificity ( $\mathrm{Sp}$ ) for MPV were 0.66 (95\% CI; $0.59-0.73)$ and 0.60 (95\% CI; 0.43 - 0.75 ), respectively (Table 3 ). Forest plots for Se and Sp in the diagnosis of myocardial infarction are presented in Figure 3. Heterogeneity was measured by Cochran's $\mathrm{Q}$ statistic and quantified using the $\mathrm{I}^{2}$. The calculated $\mathrm{I}^{2}$ was $80 \%$ for the pooled Se, and $97 \%$ for the pooled Sp.

\begin{tabular}{ccc}
\hline \multicolumn{3}{c}{ Table 3. Summary points of diagnostic performance } \\
\hline Summary Point & Value & 95\% Confidence Interval \\
\hline Sensitivity & 0.66 & $0.59-0.73$ \\
Specificity & 0.60 & $0.43-0.75$ \\
DOR & 2.92 & $1.90-4.50$ \\
LR+ & 1.65 & $1.20-2.27$ \\
LR- & 0.56 & $0.50-0.64$ \\
Mean Threshold & $9.59 \mathrm{fl}$ & $7.97-11.21$ \\
\hline
\end{tabular}

Summary Positive LR, Negative LR, DOR. The positive likelihood ratio of MPV in the diagnosis of myocardial infarction was 1.65 (95\% CI; $1.20-2.27)$, and the negative likelihood ratio was $0.56(95 \% \mathrm{CI} ; 0.50-0.64)$. The pooled diagnostic odds ratio (DOR) was 2.92 (95\% CI; $1.90-4.50)$.

Summary Positive and Negative Predictive Values. The positive predictive value (PPV) of MPV in the diagnosis of myocardial infarction was 0.3180 , and the negative predictive value (NPV) was 0.8189 .

Mean Cut-off Value and Threshold Effect. Different positivity thresholds were used across all six diagnostic accuracy studies in this meta-analysis. The mean cut-off value for positivity was $9.59 \pm 1.55 \mathrm{fl}(95 \% \mathrm{CI} ; 7.97-11.21$ fl). A threshold effect was already presumed in this study; however, the investigator opted to measure the Spearman correlation coefficient which was 0.314 ( $\mathrm{p}$ value of 0.544 ).

Summary ROC Curve. Because of the presence of heterogeneity, the diagnostic indices were calculated using the HSROC model and the random effects model. The summary ROC curve is shown in the figure below (Figure 4). Also shown in Figure 4 are the ff: the summary operating point (summary sensitivity and summary specificity), the $95 \%$ confidence region around the summary operating point, and the $95 \%$ prediction region. The confidence region is a measure of withinstudy uncertainty caused by sampling variability, while the prediction region is a measure of between-study variability. ${ }^{8,13}$ Estimates of variance under the bivariate model showed (logitSe) of 0.1239 and (logitSp) of 0.7084 . 


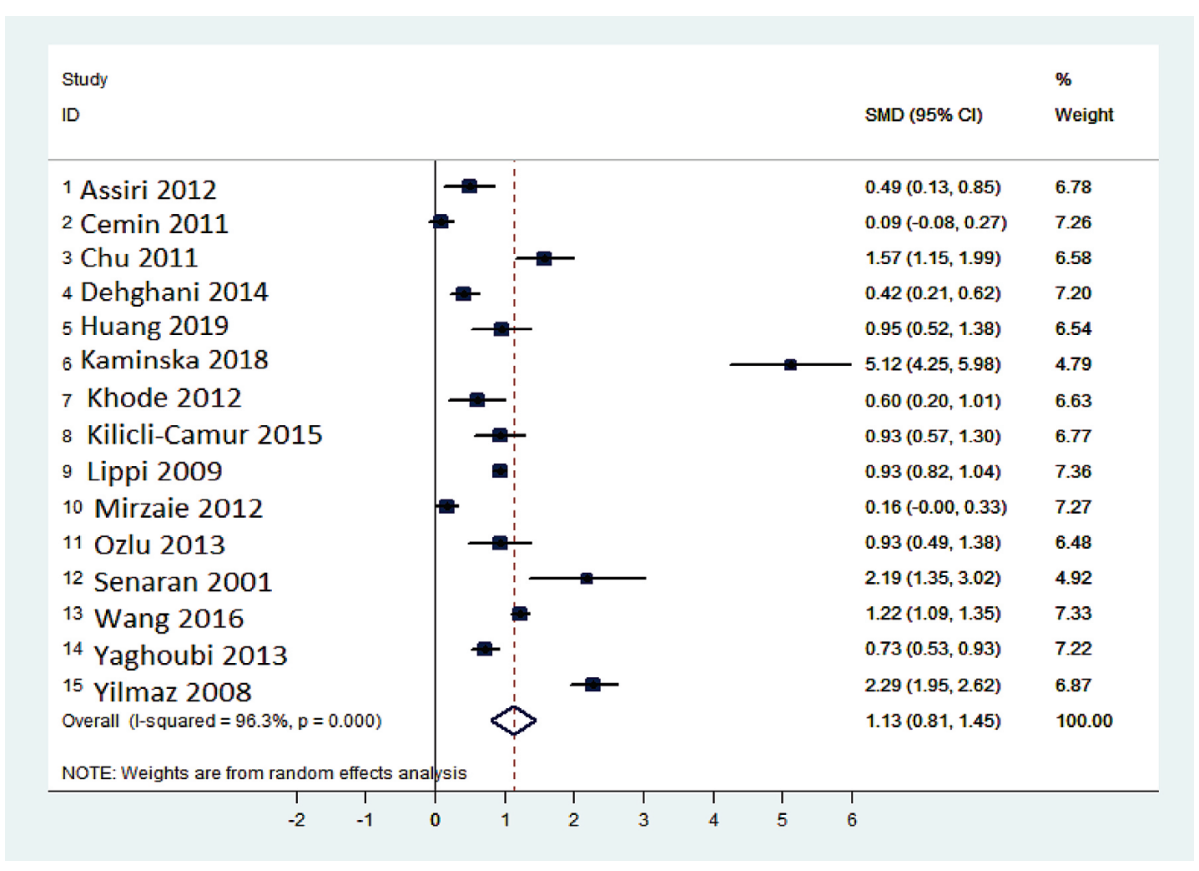

Figure 2. Forest plot of standard mean difference of MPV in those with MI and non-MI controls.

$\begin{array}{lrrrrrr}\text { Study } & \text { TP } & \text { FP } & \text { FN } & \text { TN } & \text { Sensitivity }(95 \% \text { Cl) } & \text { Specificity }(95 \% \text { Cl) } \\ \text { Cemin 2011 } & 102 & 1011 & 31 & 827 & 0.77[0.69,0.84] & 0.45[0.43,0.47] \\ \text { Chu 2011 } & 22 & 57 & 6 & 197 & 0.79[0.59,0.92] & 0.78[0.72,0.83] \\ \text { Dehghani 2014 } & 138 & 512 & 54 & 342 & 0.72[0.65,0.78] & 0.40[0.37,0.43] \\ \text { Khode 2012 } & 22 & 48 & 17 & 41 & 0.56[0.40,0.72] & 0.46[0.35,0.57] \\ \text { Kilicli-Camur 2015 } & 32 & 17 & 38 & 113 & 0.46[0.34,0.58] & 0.87[0.80,0.92] \\ \text { Wang 2016 } & 613 & 347 & 267 & 347 & 0.70[0.67,0.73] & 0.50[0.46,0.54]\end{array}$

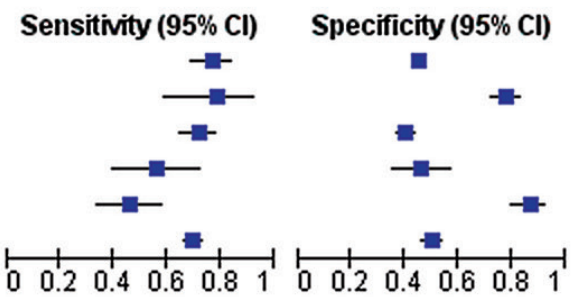

Figure 3. Forest Plot of Diagnostic Accuracy Studies.

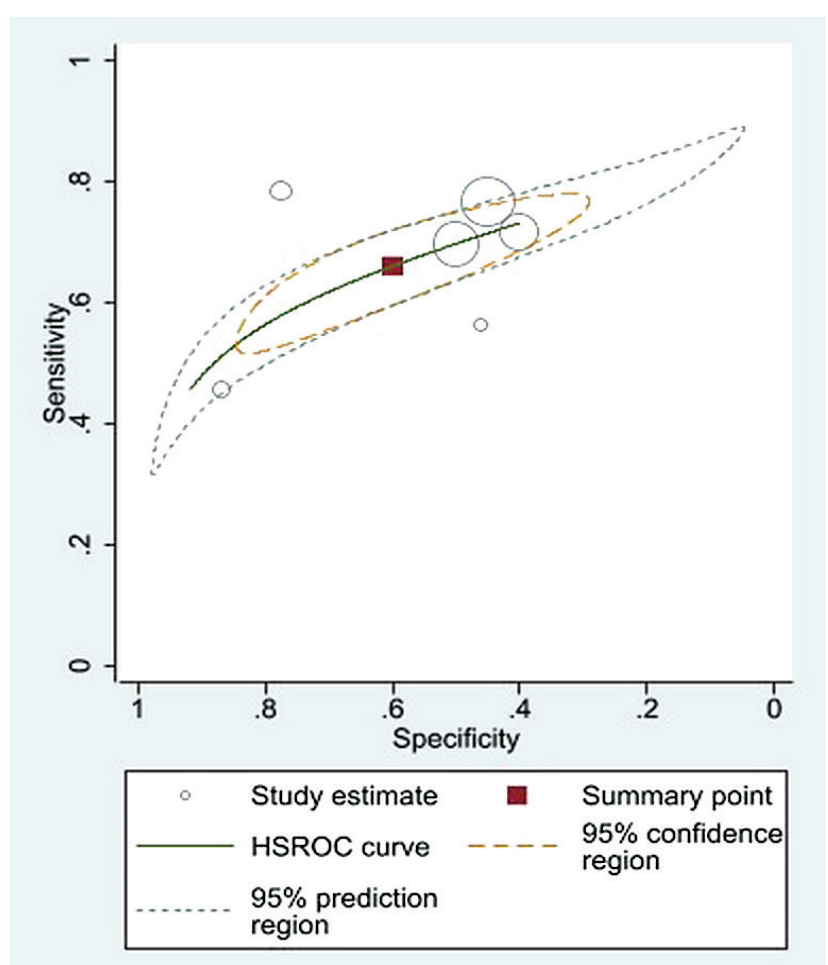

Figure 4. Summary ROC Curve of MPV in the Diagnosis of Myocardial Infarction.

\section{DISCUSSION}

\section{Summary of Main Results}

This meta-analysis compiled cross-sectional studies and diagnostic accuracy studies on the diagnostic performance of mean platelet volume in the diagnosis of myocardial infarction among adult patients with angina and/or its equivalents. A total of fifteen articles met the inclusion criteria and were deemed eligible for subsequent metaanalysis, and among which, six studies were diagnostic accuracy studies. The overall mean MPV value of those with MI (9.702 fl; 95\% CI 9.07 - 10.33) was higher than in those of the non-MI control group $(8.85 \mathrm{fl}$; $95 \%$ CI 8.23 - 9.46). Interpretation of the calculated t-value of 2.0827 showed that there was a significant difference in the mean MPV values of those with MI and those of the non-MI controls. The summary sensitivity (Se) and specificity (Sp) for MPV were 0.66 (95\% CI; $0.59-0.73)$ and 0.60 (95\% CI; $0.43-0.75)$, respectively. The pooled diagnostic odds ratio (DOR) was $2.92(95 \% \mathrm{CI} ; 1.90-4.50)$. The positive likelihood ratio of MPV in the diagnosis of myocardial infarction was 1.65 (95\% CI; 1.20 - 22.27), and the negative likelihood ratio was 0.56 (95\% CI; 0.50 - 0.64). The positive predictive value (PPV) of MPV in the diagnosis of myocardial infarction was 0.3180 , and the negative predictive value (NPV) was 0.8189 . Across all fifteen included studies, a high degree of heterogeneity 
was measured at $\mathrm{I}^{2}$ of $96.3 \%$. Across the six diagnostic accuracy studies, estimates of variance under the bivariate model showed logitSe of 0.1239 and logitSp of 0.7084 . Under the HSROC model, the $95 \%$ prediction region was larger than the $95 \%$ confidence region, signifying high heterogeneity. ${ }^{13}$

\section{Summary of Statistical Findings}

It was established that there was a significant difference between the mean MPV values in those with MI compared to those of the non-MI controls. This study also showed that overall, mean MPV values of those with MI were higher than in those without. However, in diagnostic accuracy studies, further statistical data must be studied in order to view this information in terms of values that are of actual clinical value.

A high degree of heterogeneity was expected in metaanalyses of diagnostic test accuracy. The most common cause of which was the varied cut-off points or thresholds used by each study. ${ }^{11,13}$ Because different positivity thresholds were used across all the diagnostic accuracy studies in this meta-analysis, a SROC curve was used to summarize diagnostic performance. For this metaanalysis, the generated SROC curve was located slightly above the line of symmetry, which implies that MPV had a low discriminatory power in identifying the presence or absence of MI. This data coincided well with the pooled diagnostic odds ratio (DOR) of 2.92, which indicates that MPV indeed has discriminatory power, but at a low level.

The pooled sensitivity and specificity were at 0.66 and 0.60 , respectively. This suggests that MPV demonstrates the ability to detect MI, as the ability to correctly identify those without the disease.

Clinically, likelihood ratios are much more useful than sensitivity and specificity because they provide a summary of how many times more (or less) likely patients with the disease are to have that particular result than patients without the disease. ${ }^{27}$ In this meta-analysis, the calculated positive likelihood ratio was 1.65. Since $\mathrm{LR}+\mathrm{s}$ greater than 1 mean that a positive test is more likely to occur in people with the disease than in people without the disease, this means that for a patient with elevated MPV values, he is 1.65 times more likely to have MI. ${ }^{27}$ On the other hand, LR-s less than 1 mean that a negative test is less likely to occur in people with the disease compared to people without the disease. ${ }^{27}$ In this meta-analysis, the negative likelihood ratio was 0.56 . Thus, this means that a normal MPV value is 0.56 times less likely to occur in individuals with MI than in those without the disease. However, it must be emphasized that since the LR+ of 1.65 is quite low (below 10), an elevated MPV value cannot effectively "rule-in" MI. Moreover, since the LR- of 0.56 is not very low (below 0.1 ), a normal MPV value also cannot effectively "rule-out" MI.

In addition, the PPV of 0.3180 tells us that among those with an elevated MPV value, the proportion of patients that can correctly be identified as having MI was $31.80 \%$. Moreover, the NPV of 0.8189 shows that among those with a normal MPV value, the proportion of patients that can correctly be identified without the disease was $81.89 \%$. This data suggests that a normal MPV can correctly identify patients without MI $81.89 \%$ of the time.

In addition, identification of the appropriate threshold or cut-off of a test was not possible with the SROC curves. ${ }^{13}$ For this study, the computed mean threshold value was $9.59 \mathrm{fl}$, which is below the usual upper limit of normal employed by many hospital laboratories. At this point, it should be noted that several studies have determined varying normal reference ranges for healthy individuals, with a minimum value of $7.0 \mathrm{fl}$ to a maximum value of $11.7 \mathrm{fl}^{5,6,28,29}$ The study by Korniluk et al., signified the need to establish individual reference values for MPV by laboratory, and in order to do so, each laboratory should enroll adequate number of individuals with respect to gender, age, and ethnicity. ${ }^{29,30}$

\section{Quality of evidence}

The assessment for quality of evidence is summarized in the table of Summary of Findings (Table 4). The outcome on the significant difference in mean MPV values was deemed of moderate quality. ${ }^{31}$

\section{Strengths and weaknesses of included studies}

This analysis contained several studies with similar results and conclusions: that MPV was significantly higher in those with MI; and that elevated MPV values are associated with MI. The studies also occurred in similar population groups. However, it is important to note that six out of fifteen articles were case-control studies. This may affect the estimation of accuracy since there was an inherent bias in first choosing cases of the disease before looking for a correlation with MPV. Upon quality assessment using the QUADAS2 tool, several factors contributed to weakness of the included studies. Six out of 15 articles did not employ exclusion criteria. Under the index test domain, six case-control studies already had knowledge of the results of the reference standard before interpreting the index test. Lastly, under concern for applicability, one article used a study population of patients who underwent angiography.

\section{Strengths and weaknesses of the review process}

Limitations of search strategy. There were no limitations imposed on the search strategy. No filters, as well as no language restrictions were employed.

Quality assessment and data extraction. There were a few studies that were identified with missing information. The authors were contacted by the reviewers. Most did not respond, and the few who did could not give the information that was inquired because either the data was already inaccessible, or that the data was not part of the planned dataset of the study.

Limitations in the review analyses. There were few systematic reviews, but this was the first meta-analysis that attempted to summarize diagnostic accuracy measures of MPV values in the diagnosis of myocardial infarction. This analysis was limited by substantial heterogeneity especially with the threshold value. The threshold effect could not be explored due to statistical limitations. 


\section{Table 4. Summary of Findings}

Among adult patients presenting with angina and/or its equivalents, what is the diagnostic performance of an elevated mean platelet volume value in the diagnosis of acute myocardial infarction?

Population Adult patients with angina and/or its equivalents

Setting Tertiary hospitals (majority in Asia with some in Europe and North America)

Index Test Mean platelet volume measure by automated hematology analyzers

Reference Standard Diagnostic criteria and guidelines set by Cardiology societies

Studies $\quad$ Fifteen studies consisting of eight diagnostic accuracy articles and seven cross-sectional studies.

\begin{tabular}{|c|c|c|c|c|}
\hline Outcomes & Summary & $\begin{array}{l}\text { No. of participants } \\
\text { (studies) }\end{array}$ & Implications & $\begin{array}{l}\text { Quality of } \\
\text { Evidence (Grade) }\end{array}$ \\
\hline $\begin{array}{l}\text { Significant difference } \\
\text { in mean MPV } \\
\text { (in } 15 \text { studies) }\end{array}$ & $\begin{array}{l}\text { Mean in those with } \mathrm{Ml} 9.702 \mathrm{fl} \\
(95 \% \mathrm{Cl} ; 9.07-10.33) \\
\text { Mean in non-Ml control group } \\
8.85 \mathrm{fl}(95 \% \mathrm{Cl} 8.23-9.46) \\
\mathrm{SMD} 1.131(95 \% \mathrm{Cl} ; 0.81-1.45) \\
\text { t-value } 2.0827 \text { with degrees of } \\
\text { freedom at } 27.9\end{array}$ & $9748(15)$ & $\begin{array}{l}\text { MPV values are higher in those with MI than those without. } \\
\text { A positive association is seen between increasing MPV values } \\
\text { and those with MI. There is a significant difference in the mean } \\
\text { MPV values of those with MI compared with those without. }\end{array}$ & $\begin{array}{l}+++- \\
\text { Moderate }\end{array}$ \\
\hline $\begin{array}{l}\text { Diagnostic performance } \\
\text { of MPV (in } 6 \text { studies) }\end{array}$ & $\begin{array}{l}\text { Sensitivity } \\
0.66(95 \% \mathrm{Cl} ; 0.59-0.73) \\
\text { Specificity } \\
0.60(95 \% \mathrm{Cl} ; 0.43-0.75) \\
\text { DOR } 2.92(95 \% \mathrm{Cl} ; 1.90-4.50) \\
\text { LR+ } 1.65(95 \% \mathrm{Cl} ; 1.20-22.27) \\
\text { LR- } 0.56(95 \% \mathrm{Cl} ; 0.50-0.64) \\
\text { PPV } 0.3180 \\
\text { NPV } 0.8189\end{array}$ & $5017(6)$ & $\begin{array}{l}\text { In patients with MI, } 66 \% \text { of them can be identified with elevated } \\
\text { MPV values. In those without MI, } 60 \% \text { can be correctly identified } \\
\text { by normal MPV. MPV values can discriminate between those } \\
\text { who have MI and those without, but at low levels. For a patient } \\
\text { with elevated MPV values, he is } 1.65 \text { times more likely to have } \\
\text { MI. On the other hand, a normal MPV value is } 0.56 \text { times less } \\
\text { likely to occur in individuals with MI than in those without } \\
\text { the disease. The PPV of } 0.3180 \text { tells us that among those with } \\
\text { an elevated MPV value, the proportion of patients correctly } \\
\text { diagnosed with MI was } 31.80 \% \text {. The NPV of } 0.8189 \text { shows } \\
\text { that among those with a normal MPV value, the proportion of } \\
\text { patients correctly identified without the disease was } 81.89 \% \text {. }\end{array}$ & $\begin{array}{l}++-\cdot \\
\text { Low }\end{array}$ \\
\hline
\end{tabular}

Caution: The results on this table should not be interpreted in isolation from the results of the individual included studies contributing to each summary test accuracy measure. These are reported in the main body of the text of the review.

\section{Overall completeness and applicability of evidence}

As a diagnostic test for prediction of MI, perhaps the most appropriate function of mean platelet volume is for triaging adult patients with angina and/or its equivalents who are suspected of having myocardial infarction. This can be supported by the findings of this study, which has determined that a significant difference exists in the mean MPV values between those with MI and those without. Additionally, it has been established that those with MI have greater MPV values than those without.

The threshold at which we define an MPV value as "elevated" or "normal" ideally should have been identified with this study. However, a high degree of heterogeneity posed a challenge to this objective such that current statistical methods for obtaining diagnostic performance summaries do not allow for this identification. The reviewers thus opted to get the mean threshold value at which the articles defined an elevated value, which was $9.59 \mathrm{fl}$.

The main evidence obtained by this meta-analysis was a summary of diagnostic accuracy estimates across similar studies. Although the sensitivity and specificity were moderately high, what were perhaps more valuable for this study were the predictive values, likelihood ratios and diagnostic odds ratio, which tell us that MPV indeed has discriminatory value but at a low level.

\section{Limitations of the Study}

This study employed only articles that differentiated the subgroups of ACS. Those that did not identify subgroups were not included in this study. Further, investigation of heterogeneity ideally should have been done. A funnel plot could have been generated to examine for the presence of asymmetry, which would suggest possible publication bias which usually occurs where studies with negative results are less likely to be published than studies with positive results. ${ }^{32}$ However, a funnel plot could not be generated with the program used for the meta-analysis. The statistical command package "metandi" in the program STATA which was used in this study currently has no capability to generate a funnel plot. Meta-regression analysis and a funnel plot analysis ideally should have been done to investigate the threshold effect and identify any outlier studies that may have affected the outcome of this study.

\section{Potential biases in the review process}

Few articles in this study had a case-control design and therefore induced bias in the domains of patient selection and interpretation of the index test. Additionally, articles that did not differentiate the ACS subgroups were not included in this study, and it is of interest to note the outcome if these studies provided the needed information.

\section{CONCLUSION}

\section{Implications for practice}

The intended role for MPV in the diagnostic pathway of myocardial infarction would perhaps be best as a triage tool. Since MPV results are more readily available, it has the potential to guide early diagnostic decisions especially in patients who are suspected of having MI. With a DOR of 2.92, MPV values can discriminate between those who have MI and those without. To support this, it was also concluded that there is a significant difference in the mean MPV values of those with MI compared with those without; and that MPV values are higher in those with MI. Therefore, it can be implied that in a patient with a probable diagnosis of MI, a high MPV value (greater than $9.59 \mathrm{fl}$ ) can discriminate cases of actual disease and warrant further testing according to the reference standard. Additionally, it can also be implied that a diagnosis of MI is less likely in a patient with normal MPV values. 
For a patient with angina presenting with elevated MPV values, it is 1.65 times more likely that he has MI. For patients with the disease, a substantial $66 \%$ of these cases can be correctly flagged by an elevated MPV value. Additionally, the NPV of 0.8189 shows that among those with a normal MPV value, the proportion of patients correctly identified without MI was $81.89 \%$. Thus, it is implied that the decision to treat a patient with angina or its equivalents as a case of MI could be supported by an elevated MPV value. Moreover, a normal MPV value can correctly identify patients without MI $81.89 \%$ of the time. With that said, it should be taken into consideration that MPV's low discriminatory power and its levels of sensitivity and specificity cannot warrant its use as a screening tool to decide who gets treated for the disease.

\section{Implications for research}

The main drawback of meta-analyses of diagnostic test accuracy studies is that summarized data obtained from analysis are indirect forms of evidence and cannot be used to make generalized conclusions. Being the first metaanalysis of its kind, this study has shown that marked heterogeneity can be expected especially with studies that have varied thresholds. The reviewers therefore recommended that for further studies, the following measures may be implemented. A subgroup analysis of studies comparing those with ACS and those without may be done. Meta-regression analysis and funnel plot graphs may be done to identify outlier studies. Investigation into the threshold effect would be most beneficial. Perhaps in future studies, more advanced statistical methods may already be available which can correctly identify the threshold cut-off for positivity. In addition, further efforts to identify unpublished studies may be done in order to ensure a greater range of included studies. Broad guidelines in the implementation of this study are tabulated in Appendix 5.

Abbreviations used in this protocol study. $M P V$ (mean platelet volume); $M I$ (myocardial infarction); ACS (acute coronary syndrome); $A U C$ (area under the curve); $R O C$ (receiver operating characteristics); SROC (summary of ROC); HSROC (hierarchical SROC); CBC (complete blood count); NSTEMI (non-ST segment elevation MI); STEMI (ST segment elevation MI); UA (unstable angina); $E C G$ (electrocardiogram); DTA (diagnostic test accuracy)

\section{FUNDING SOURCE}

This study was self-funded.

\section{CONFLICT OF INTEREST}

No conflict of interest was declared.

\section{ACKNOWLEDGMENTS}

The authors would like to acknowledge the Chairman of the Department of Pathology of Perpetual Succour Hospital, Dr. Ibarra T. Panopio, and the Training Officer, Dr. Susan B. Abanilla, for providing this opportunity to conduct this research. The reviewers also wish to thank Dr. Ma. Nilepta B. Lim for her encouragement in commencing a study focused on Clinical Pathology. Finally, the researchers wish to thank Dr. Shanida L. Camomot for her expertise and continual guidance to the reviewers in their attempt to accomplish this novel level of research study.

\section{STATEMENT OF AUTHORSHIP}

All authors certified fulfillment of ICMJE authorship criteria.

\section{AUTHOR DISCLOSURE}

The authors declared no conflict of interest.

\section{FUNDING SOURCE}

None.

\section{REFERENCES}

1. World Health Organization. Cardiovascular Diseases. Available from www.who.int/health-topics/ cardiovascular-diseases/\#tab=tab_1.

2. Amsterdam EA, Wenger NK, Brindis RG, et al. 2014 AHA/ACG guideline for the management of patients with non-ST-elevation acute coronary syndromes: executive summary: a report of the American College of Cardiology/American Heart Association Task Force on Practice Guidelines. Circulation. 2014;130(25):2354-94. PMID: 25249586. https://doi. org/10.1161/CIR.0000000000000133.

3. Lippi G, Filippozzi L, Salvagno GL, et al. Increased mean platelet volume in patients with acute coronary syndromes. Arch Pathol Lab Med. 2009;133(9):14413. PMID: 19722752. https://doi.org/10.1043/15432165-133.9.1441.

4. Mirzaie AZ, Abolhasani M, Ahmadinejad B, Panahi M. Platelet count and MPV, routinely measured but ignored parameters used in conjunction with the diagnosis of acute coronary syndrome: single study center in Iranian population, 2010. Med J Islam Repub Iran. 2012;26(1):17-21. PMID: 23482685. PMCID: PMC3587888.

5. Demirin H, Ozhan H, Ucgun T, et al. Normal range of mean platelet volume in healthy subjects: insight from a large epidemiologic study. Thromb Res. 2011;128(4):358-60. PMID:21620440. https://doi. org/10.1016/j.thromres.2011.05.007.

6. Latger-Cannard V, Hoarau M, Salignac S, Baumgart D, NUrdem P, Lecompte T. Mean platelet volume: comparison of three analysers towards standardization of platelet morphological phenotype. Int $\mathrm{J} \mathrm{Lab}$ Hematol.2012;34(3):300-10.PMID: 22225539. https:// doi.org/10.1111/j.1751-553X.2011.01396.x.

7. Chu H, Chen WL, Huang CC, et al. Diagnostic performance of mean platelet volume for patients with acute coronary syndrome visiting an emergency department with acute chest pain: the Chinese scenario. Emerg Med J. 2011;28)7):569-74. PMID: 20650916. https://doi.org/10.1136/emj.2010.093096.

8. Harbord RM, Whiting P. Metandi: meta-analysis of diagnostic accuracy using hierarchical logistic regression. The Stata Journal. 2009;9:211-29. https://journals.sagepub.com/doi/pdf/10.1177/ 1536867 X0900900203. 
9. Wang J, Leeflang M. Recommended software/ packages for meta-analysis of diagnostic accuracy. J Lab Precis Med. 2019;4:22.

10. Campbell JM, Klugar M, Ding S, et al. Chapter 9: Diagnostic test accuracy systematic reviews. In: Aromataris E, Munn Z, eds. JBA Manual for evidence synthesis. JBI; 2020. Available from https:// synthesismanual.jbi.global. https://doi.org/10.46658/ JBIMES-20-10.

11. Macaskill P, Gatsonis C, Deeks J, Harbord R, Takwoingi Y. Chapter 10: Analysing and presenting results. In: Deeks JJ, Bossuyt PM, Gatsonis C, eds. Version 1.0. Cochrane handbook for systematic reviews of diagnostic test accuracy. London: The Cochrane Collaboration; 2010. Available from http:// srdta.cochrane.org/.

12. Borenstein M, Hedges LV, Higgins JPT, Rothstein HR. Introduction to meta-analysis: statistical meta-analysis with applications. UK: John Wiley and Sons Ltd.; 2009.

13. Bossuyt PM, Davenport C, Deeks J, Hyde C, Leeflang M, Scholten R. Chapter 11: Interpreting results and drawing conclusions. In: Deeks JJ, Bossuyt PM, Gatsonis C, eds, Cochrane handbook for systematic reviews of diagnostic test accuracy version 0.9 . The Cochrane Collaboration; 2013. Available from: http:// srdta.cochrane.org/.

14. Assiri, Abdullah S., et al. Diagnostic importance of platelet parameters in patients with acute coronary syndrome admitted to a tertiary care hospital in southwest region. Saudi Arabia. J Saudi Heart Assoc. 2012;24(1):17-21. PMID: 23960663. PMCID: PMC3727553. https://doi.org/10.1016/j. jsha.2011.08.004.

15. Cemin R, Donazzan L, Lippi G, Clari F, Daves M. Blood cells characteristics as determinants of acute myocardial infarction. Clin Chem Lab Med. 2011;49(7):1231-6. PMID: 21534844. https://doi. org/10.1515/CCLM.2011.183.

16. Dehghani M R, Taghipour-Sani L, Rezaei Y, Rostami R. Diagnostic importance of admission platelet volume indices in patients with acute chest pain suggesting acute coronary syndrome. Indian Heart J. 2014;66(6): 622-8. PMID: 25634396. PMCID: PMC4310955. https://doi.org/10.1016/j.ihj.2014.10.415.

17. Huang HL, Chen CH, Kung CT, et al. Clinical utility of mean platelet volume and immature platelet fraction in acute coronary syndrome. Biomed J. 2019;42(2): 107-15. PMID: 31130246. PMCID: PMC6541877. https://doi.org/10.1016/j.bj.2018.12.005.

18. Kamińska J, Koper OM, Siedlecka-Czykier E, Matowicka-Karna J, Bychowski J, Kemona H. The utility of inflammation and platelet biomarkers in patients with acute coronary syndromes. Saudi J Biol Sci. 2018;25(7):1263-71. PMID: 30505168. PMCID: PMC6252018. https://doi.org/10.1016/j.sjbs. 2016.10.015.

19. Khode V, Sindhur J, Kanbur D, Ruikar K, Nallulwar S. Mean platelet volume and other platelet volume indices in patients with stable coronary artery disease and acute myocardial infarction: a case control study. J Cardiovasc Dis Res. 2012;3(4):272-5. PMID: 23233769. PMCID: PMC3516005. https://doi. org/10.4103/0975-3583.102694.
20. Kiliçli-Çamur N, Demirtunc C, Konuralp C, Eskiser A, Basaran Y. Could mean platelet volume be a predictive marker for acute myocardial infarction? Medical Science Monitor. 2005;11(8):CR387-92.

21. Özlü MF, Öztürk S, Ayhan SS, et al. Predictive value of mean platelet volume in young patients with nonST-segment elevation acute coronary syndromes: a retrospective observational study. Anadolu Kardiyol Derg. 2013;13(1):57-61. PMID: 23086804. https:// doi.org/10.5152/akd.2013.007.

22. Şenaran H, Ileri M, Altinbas A. et al. Thrombopoietin and mean platelet volume in coronary artery disease. Clin Cardiol. 2001;24(5):405-8. https://www.ncbi.nlm. nih.gov/pmc/articles/PMC6655056/pdf/CLC-24-405. pdf.

23. Wang X, Xu XL, Li XM, Zhao R, Yang X, Cong HL. Diagnostic value of mean platelet volume combined with troponin I for acute coronary syndrome. Am J Med Sci. 2016;352(2):159-65. PMID: 27524214. https://doi.org/10.1016/j.amjms.2016.04.014.

24. Yaghoubi A, Golmohamadi Z, Alizadehasi A, Azarfarin R. Role of platelet parameters and haematological indices in myocardial infarction and unstable angina. J Pak Med Assoc. 2013;63(9):1133-7. PMID: 24601192.

25. Yilmaz MB, Gokhan C, Guray Y, et al. Role of mean platelet volume in triagging acute coronary syndromes. J Thromb Thrombolysis. 2008;26(1):4954. PMID: 17705053. https://doi.org/10.1007/s11239007-0078-9.

26. Buoro S, Seghezzi M, Manenti B, et al. Biological variation of platelet parameters determined by the Sysmex XN hematology analyzer. Clin Chim Acta. 2017;470:125-32. PMID: 28479317. https://doi.org/ 10.1016/j.cca.2017.05.004.

27. Akobeng AK. Understanding diagnostic tests 2: likelihood ratios, pre-and post-test probabilities and their use in clinical practice. Acta Paediatr. 2007;96(4):487-91. PMID: 17306009. https://doi. org/10.1111/j.1651-2227.2006.00179.x.

28. Cho SY, Lee HJ, Lee W-I, Park TS. Mean platelet volume according to the ethnic difference. Int J Lab Hematol. 2014;36(5);587-8. PMID: 24206452 https://doi.org/10.1111/ijlh.12162.

29. Korniluk A, Koper-Lenkiewicz OM, Kamińska J, Kemona H, Dymicka-Piekarska V. Mean platelet volume (MPV): new perspectives for an old marker in the course and prognosis of inflammatory conditions. Mediators Inflamm. 2019: 9213074. PMID: 31148950. PMCID: PMC6501263. https://doi. org/10.1155/2019/9213074.

30. Noris P, Melazzini F, Balduini CL. New roles for mean platelet volume measurement in the clinical practice? Platelets. 2016;27(7):607-12. PMID: 27686008. https://doi.org/10.1080/09537104.2016.1224828.

31. Schünemann H, Brożek J, Guyatt G, Oxman A. GRADE handbook for grading quality of evidence and strength of recommendations. Updated October 2013. The GRADE Working Group; 2013. Available from guidelinedevelopment.org/handbook.

32. Bradburn MJ, Deeks JJ, Altman DG. Metan-an alternative meta-analysis command. Stata Technical Bulletin. 1999;8(44). https://econpapers.repec.org/ article/tsjstbull/y_3a1999_3av_3a8_3ai_3a44_3asge24. htm. 


\section{APPENDICES}

Appendix 1. PRISMA Checklist

\begin{tabular}{|c|c|c|}
\hline Section/Topic & \# & Reported on Page \# \\
\hline \multicolumn{3}{|l|}{ TITLE } \\
\hline Title & 1 & Identify the report as a systematic review, meta-analysis, or both. \\
\hline \multicolumn{3}{|l|}{ ABSTRACT } \\
\hline Structured summary & 2 & $\begin{array}{l}\text { Provide a structured summary including, as applicable: background; objectives; data sources; study eligibility } \\
\text { criteria, participants, and interventions; study appraisal and synthesis methods; results; limitations; conclusions } \\
\text { and implications of key findings; systematic review registration number. }\end{array}$ \\
\hline \multicolumn{3}{|l|}{ INTRODUCTION } \\
\hline Rationale & 3 & Describe the rationale for the review in the context of what is already known. \\
\hline Objectives & 4 & $\begin{array}{l}\text { Provide an explicit statement of questions being addressed with reference to participants, interventions, } \\
\text { comparisons, outcomes, and study design (PICOS). }\end{array}$ \\
\hline \multicolumn{3}{|l|}{ METHODS } \\
\hline Protocol and registration & 5 & $\begin{array}{l}\text { Indicate if a review protocol exists, if and where it can be accessed (e.g., Web address), and, if available, provide } \\
\text { registration information including registration number. }\end{array}$ \\
\hline Eligibility criteria & 6 & $\begin{array}{l}\text { Specify study characteristics (e.g., PICOS, length of follow-up) and report characteristics (e.g., years considered, } \\
\text { language, publication status) used as criteria for eligibility, giving rationale. }\end{array}$ \\
\hline Information sources & 7 & $\begin{array}{l}\text { Describe all information sources (e.g., databases with dates of coverage, contact with study authors to identify } \\
\text { additional studies) in the search and date last searched. }\end{array}$ \\
\hline Search & 8 & $\begin{array}{l}\text { Present full electronic search strategy for at least one database, including any limits used, such that it could be } \\
\text { repeated. }\end{array}$ \\
\hline Study selection & 9 & $\begin{array}{l}\text { State the process for selecting studies (i.e., screening, eligibility, included in systematic review, and, if applicable, } \\
\text { included in the meta-analysis). }\end{array}$ \\
\hline Data collection process & 10 & $\begin{array}{l}\text { Describe method of data extraction from reports (e.g., piloted forms, independently, in duplicate) and any } \\
\text { processes for obtaining and confirming data from investigators. }\end{array}$ \\
\hline Data items & 11 & $\begin{array}{l}\text { List and define all variables for which data were sought (e.g., PICOS, funding sources) and any assumptions and } \\
\text { simplifications made. }\end{array}$ \\
\hline $\begin{array}{l}\text { Risk of bias in individual } \\
\text { studies }\end{array}$ & 12 & $\begin{array}{l}\text { Describe methods used for assessing risk of bias of individual studies (including specification of whether this was } \\
\text { done at the study or outcome level), and how this information is to be used in any data synthesis. }\end{array}$ \\
\hline Summary measures & 13 & State the principal summary measures (e.g., risk ratio, difference in means). \\
\hline Synthesis of results & 14 & $\begin{array}{l}\text { Describe the methods of handling data and combining results of studies, if done, including measures of } \\
\text { consistency }\left(e . g ., I^{2}\right) \text { for each meta-analysis. }\end{array}$ \\
\hline Risk of bias across studies & 515 & $\begin{array}{l}\text { Specify any assessment of risk of bias that may affect the cumulative evidence (e.g., publication bias, selective } \\
\text { reporting within studies). }\end{array}$ \\
\hline Additional analyses & 16 & $\begin{array}{l}\text { Describe methods of additional analyses (e.g., sensitivity or subgroup analyses, meta-regression), if done, } \\
\text { indicating which were pre-specified. }\end{array}$ \\
\hline \multicolumn{3}{|l|}{ RESULTS } \\
\hline Study selection & 17 & $\begin{array}{l}\text { Give numbers of studies screened, assessed for eligibility, and included in the review, with reasons for exclusions } \\
\text { at each stage, ideally with a flow diagram. }\end{array}$ \\
\hline Study characteristics & 18 & $\begin{array}{l}\text { For each study, present characteristics for which data were extracted (e.g., study size, PICOS, follow-up period) } \\
\text { and provide the citations. }\end{array}$ \\
\hline Risk of bias within studies & s 19 & Present data on risk of bias of each study and, if available, any outcome-level assessment (see Item 12). \\
\hline $\begin{array}{l}\text { Results of individual } \\
\text { studies }\end{array}$ & 20 & $\begin{array}{l}\text { For all outcomes considered (benefits or harms), present, for each study: (a) simple summary data for each } \\
\text { intervention group and (b) effect estimates and confidence intervals, ideally with a forest plot. }\end{array}$ \\
\hline Synthesis of results & 21 & Present results of each meta-analysis done, including confidence intervals and measures of consistency. \\
\hline Risk of bias across studies & 522 & Present results of any assessment of risk of bias across studies (see Item 15). \\
\hline Additional analysis & 23 & Give results of additional analyses, if done (e.g., sensitivity or subgroup analyses, meta-regression [see Item 16]). \\
\hline \multicolumn{3}{|l|}{ DISCUSSION } \\
\hline Summary of evidence & 24 & $\begin{array}{l}\text { Summarize the main findings including the strength of evidence for each main outcome; consider their } \\
\text { relevance to key groups (e.g., health care providers, users, and policy makers). }\end{array}$ \\
\hline Limitations & 25 & $\begin{array}{l}\text { Discuss limitations at study and outcome level (e.g., risk of bias), and at review level (e.g., incomplete retrieval of } \\
\text { identified research, reporting bias). }\end{array}$ \\
\hline Conclusions & 26 & $\begin{array}{l}\text { Provide a general interpretation of the results in the context of other evidence, and implications for future } \\
\text { research. }\end{array}$ \\
\hline \multicolumn{3}{|l|}{ FUNDING } \\
\hline Funding & 27 & $\begin{array}{l}\text { Describe sources of funding for the systematic review and other support (e.g., supply of data); role of funders for } \\
\text { the systematic review. }\end{array}$ \\
\hline
\end{tabular}

doi:10.1371/journal.pmed.1000100.t001 


\begin{tabular}{|c|c|}
\hline Specification & Details \\
\hline \multicolumn{2}{|l|}{ Authors } \\
\hline \multicolumn{2}{|l|}{ Year } \\
\hline \multicolumn{2}{|l|}{ Title } \\
\hline \multicolumn{2}{|l|}{ Journal } \\
\hline \multicolumn{2}{|l|}{ Volume } \\
\hline \multicolumn{2}{|l|}{ Issue / Number } \\
\hline \multicolumn{2}{|l|}{ Pages } \\
\hline \multicolumn{2}{|l|}{ Population } \\
\hline \multicolumn{2}{|l|}{ Inclusion criteria } \\
\hline \multicolumn{2}{|l|}{ Exclusion criteria } \\
\hline \multicolumn{2}{|l|}{ Index test } \\
\hline \multicolumn{2}{|l|}{ Comparator } \\
\hline \multicolumn{2}{|l|}{ Outcomes } \\
\hline \multicolumn{2}{|l|}{ Methodology } \\
\hline \multicolumn{2}{|l|}{ Study design } \\
\hline \multicolumn{2}{|l|}{ Time frame } \\
\hline \multirow{2}{*}{\multicolumn{2}{|c|}{$\frac{\text { Decision (Include/Exclude) }}{\text { Basis for decision }}$}} \\
\hline & \\
\hline
\end{tabular}

\begin{tabular}{l}
$\begin{array}{l}\text { Appendix 3. Data Extraction Table } \\
\text { Study No. }\end{array}$ \\
\hline Author, Year \\
\hline Study Design \\
\hline Country Study 1 \\
\hline Study Population \\
\hline w/ Exclusion Criteria \\
\hline Control Group \\
\hline Analyzer used \\
\hline Timing of Test \\
\hline Outcomes \\
\hline Mean MPV in MI \\
\hline Mean MPV in Control \\
\hline Sensitivity \\
\hline Specificity \\
\hline Cut-off Threshold \\
\hline
\end{tabular}

\begin{tabular}{|c|c|c|c|c|}
\hline Domain & Patient Selection & Index Test & Reference Standard & Flow and Timing \\
\hline Description & $\begin{array}{l}\text { Described the method } \\
\text { of patient selection } \\
\text { Describe included patients }\end{array}$ & $\begin{array}{l}\text { Describe the index test } \\
\text { and how it was conducted } \\
\text { and interpreted }\end{array}$ & $\begin{array}{l}\text { Describe the reference } \\
\text { standard and how it was } \\
\text { conducted and interpreted }\end{array}$ & $\begin{array}{l}\text { Describe any patients who did not receive } \\
\text { the index tests or reference standard or } \\
\text { who were excluded from the } 2 \times 2 \text { table. } \\
\text { Describe the interval and any interventions } \\
\text { between index tests and the reference standard }\end{array}$ \\
\hline $\begin{array}{l}\text { Signalling questions } \\
\text { (Yes, No, Unclear) }\end{array}$ & $\begin{array}{l}\text { Was a consecutive } \\
\text { or random sample of } \\
\text { patients enrolled? } \\
\text { Was a case-control } \\
\text { design avoided? } \\
\text { Did the study avoid } \\
\text { inappropriate exclusions? }\end{array}$ & $\begin{array}{l}\text { Were the index test results } \\
\text { interpreted without } \\
\text { knowledge of the results of } \\
\text { the reference standard? } \\
\text { If a threshold was used, } \\
\text { was it prespecified? }\end{array}$ & $\begin{array}{l}\text { Is the reference standard } \\
\text { likely to correctly classify } \\
\text { the target condition? } \\
\text { Were the reference standard } \\
\text { results interpreted without } \\
\text { knowledge of the results } \\
\text { of the index test? }\end{array}$ & $\begin{array}{l}\text { Was there an appropriate interval between } \\
\text { index tests and reference standard? } \\
\text { Did all patients receive a reference standard? } \\
\text { Did all patients receive the same } \\
\text { reference standard? } \\
\text { Were all patients included in the analysis? }\end{array}$ \\
\hline $\begin{array}{l}\text { Risk of bias } \\
\text { (Yes, No, Unclear) }\end{array}$ & $\begin{array}{l}\text { Could the selection } \\
\text { of patients have } \\
\text { introduced bias? }\end{array}$ & $\begin{array}{l}\text { Could the conduct or } \\
\text { interpretation of the index } \\
\text { test have introduced bias? }\end{array}$ & $\begin{array}{l}\text { Could the reference standard, } \\
\text { its conduct, or its interpretation } \\
\text { have introduced bias? }\end{array}$ & Could the patient flow have introduced bias? \\
\hline $\begin{array}{l}\text { Concerns about } \\
\text { applicability }\end{array}$ & $\begin{array}{l}\text { Are there concerns that } \\
\text { the included patients } \\
\text { and setting do not match } \\
\text { the review question? }\end{array}$ & $\begin{array}{l}\text { Are there concerns that the } \\
\text { index test, its conduct, or } \\
\text { interpretation differ from } \\
\text { the review question? }\end{array}$ & $\begin{array}{l}\text { Are there concerns that the } \\
\text { target condition as defined by } \\
\text { the reference standard does not } \\
\text { match the review question? }\end{array}$ & \\
\hline
\end{tabular}

Disclaimer: This journal is OPEN ACCESS, providing immediate access to its content on the principle that making research freely available to the public supports a greater global exchange of knowledge. As a requirement for submission to the PJP, all authors have accomplished an AUTHOR FORM, which declares that the ICMJE criteria for authorship have been met by each author listed, that the article represents original material, has not been published, accepted for publication in other journals, or concurrently submitted to other journals, and that all funding and conflicts of interest have been declared. Consent forms have been secured for the publication of information about patients or cases; otherwise, authors have declared that all means have been exhausted for securing consent. 